4. Ito $M$, Horita $N$, Nagashima $A$, Kaneko $\mathbf{T}(2019)$. Carboplatin plus pemetrexed for the elderly incurable chemo-naive nonsquamous nonsmall cell lung cancer: Meta-analysis. Asia Pac J Clin Oncol. 2019 Apr;15(2):e3-e10. doi: 10.1111/ajco.12837. Epub 2018 Jan 8.PMID: 29316288

5. Tony S. Mok, Yi-Long Wu, Myung-Ju Ahn, et al (2017). Osimertinib or PlatinumPemetrexed in EGFR T790M-Positive Lung Cancer. N Engl J
Med 2017; NEJMoa1612674

376:629-640DOI:

10.1056

6. Trương Văn Sáng (2019). Đánh giá kết quả điều trị phác đồ Pemetrexed - Carboplatin trên bênh nhân ung thư biểu mô tuyến của phổi giai đoan IV. Luân văn Thac sĩ Chuyên ngành Ung thư

7. Trấn Thị Chung (2019). Đánh giá kết quả hoá tri bước 2 phác đồ Paclitaxel - Carboplatin trong ung thư phổi không tế bào nhỏ sau kháng TKI tại Bệnh viện Phổi Trung ương. Luận văn Thạc sĩ Chuyên ngành Ung thư

\title{
GIÁ TRI SIÊU ÂM TRONG CHẨN ĐOÁN CHẤN THƯƠNG VÀ VẾT THƯƠNG BỤNG
}

\section{TÓM TẮT}

Mục tiêu: Khảo sát vai trò của siêu âm trong chẩn đoán chấn thương và vết thương bụng tại Bệnh viện Đa khoa Sài Gòn. Đối tượng và phương pháp: Nghiên cứu tiến cứu mô tả cằt ngang trên tất cả bệnh nhân có chấn thương hoặc vết thương bụng được phẫu thuật tại khoa Ngoại Tổng quát Bệnh viện Đa khoa Sài Gòn từ 1/1/2019 - 31/12/2020. Kết quả: Tổng cộng có 96 trường hợp chấn thương hoăcc vết thương bụng được chẩn đoán và phẫu thuật. Siều âm phát hiện dịch tự do trong ổ bung độ nhạy $89.68 \%$, độ đăc hiệu $66,67 \%$. Siêu âm xác định vỡ tạng rỗng có độ nhạy $81,5 \%$, độ đặc hiệu $95,67 \%$. Trong võ tạng đặc siêu âm có độ chính xác: 90,6\%. Kết luận: Chấn thương và vết thương bụng là cấp cứu ngoại khoa. Chẩn đoán sớm, thái độ xử lý thích hợp giúp giảm tỷ lệ tử vong. Siêu âm đánh giá tập trung thương tổn là phương pháp chẩn đoán được lựa chọn đâu tiên giúp khảo sát thương tổn tạng trong ổ bụng. Độ nhay, độ chính xác của siêu âm trong chẩn đoán chấn thương và vết thương bụng khá cao. bung,

Tư khóa: Chấn thương bụng kín, vết thương thấu

\section{SUMMARY}

EVALUATION OF ULTRASONOGRAPHY FOR THE DIAGNOSIS OF BLUNT ABDOMINAL

\section{TRAUMA AND PENETRATING WOUND}

Objectives: Investigate the role of ultrasound in trauma and abdominal wound diagnosis at Saigon General Hospital. Subjects and methods:The prospective study describes cross-sectional sections on

${ }^{1}$ Bênh viện Đa khoa Sài Gòn

${ }^{2}$ Đai họ Y Đước TP. Hồ Chí Minh

${ }^{3}$ Đại hoc Y khoa Pham Ngoc Thạch

Chịu trách nhiệm chính: Nguyễn Hoàng Linh

Email: linhnguyen1967@gmail.com

Ngày nhận bài: 8/3/2021

Ngày phản biên khoa hoc: 9/4/2021

Ngày duyệt bài: 7/5/2021

\section{Nguyễn Hoàng Linh ${ }^{1}$, Nguyễn Đức Vũ ${ }^{1}$, Dương Văn Hải ${ }^{2}$, Nguyễn Công Minh ${ }^{3}$}

all patients with surgical trauma or abdominal wounds at the General Surgery Department of Saigon General Hospital from January 1, 2019 to December 31, 2020. Results: A total of 96 cases of trauma or abdominal injuries were diagnosed and operated. Ultrasound to detect free fluid in the bulb, sensitivity $89.68 \%$, specificity $66.67 \%$. Ultrasound to determine the hollow organ rupture with sensitivity $81.5 \%$, specificity $95.67 \%$. In the visceral solid, ultrasound has accuracy: $90.6 \%$. Conclusion: Injuries and abdominal injuries are surgical emergencies. Early diagnosis, appropriate treatment attitude helps to reduce mortality. Focused ultrasound is the primary diagnostic method of choice for the investigation of intra-abdominal damage. The sensitivity and accuracy of ultrasound in diagnosis of abdominal injuries and wounds is quite high.

Key words: Blunt abdominal trauma. Penetrating abdominal wound.

\section{I. ĐẶT VẤN ĐỀ}

Chấn thương và vết thương bụng là cấp cứu ngoại khoa thường gặp. Thương tổn các tạng trong ổ bụng có thể dẫn đến tử vong do mất máu, nhiễm trùng ổ bụng hay suy đa cơ quan nếu các thương tổn này không được chẩn đoán sớm và xử trí kip thời. Việc chẩn đoán sớm có thể gặp khó khăn do các triệu chứng ở vùng bụng bị che lấp hay chưa biểu hiện rõ trong bệnh cảnh đa chấn thương với nhiêuu thương tổn kết hợp. Do đó, mỗi bệnh nhân bị chấn thương hay vết thương vùng bụng cân được đánh giá một cách tích cực, kỹ lưỡng và toàn diện qua thăm khám lâm sàng, kết hợp với các phương tiện chẩn đoán hình ảnh và cận lâm sàng khác cho đên khi xác đinh được rằng các tạng trong ổ bụng không bị tổn thương [1].

Bác sĩ phải nhanh chóng xác đinh chẩn đoán, bệnh nhân bị tổn thương cơ quan nào, mức độ 
thương tổn ra sao, có cần phẫu thuật hay không. Việc chẩn đoán xác định ngay từ lúc bệnh mới vào viện chỉ đạt chính xác $55-65 \%$, do đó các phương tiện cận lâm sàng để hỗ trợ cho chẩn đoán rất cần thiết, cận lâm sàng khẳng định chẩn đoán nhung cũng có thể giúp thêm cho chẩn đoán. Trong khi xử trí sớm các tạng bị tổn thương là biện pháp duy nhất để hạ thấp tỷ lệ tử vong [3], [5].

Nguyên nhân thường gặp nhất của chấn thương và vết thương bụng là tai nạn giao thông, tai nạn lao động và tai nạn sinh hoạt. Trong chấn thương bụng kín tang đặc thường bị thương tổn nhiều hơn tạng rổng trong khi với vết thương bụng thì thương tổn đa dạng hơn tùy thuộc vị trí vết thương và tác nhân gây thương tích.

Siêu âm là phương tiện hình ảnh học đầu tiên được lựa chọn cho bệnh nhân chấn thương và vết thương bụng vì thời gian thực hiện nhanh, không xâm lấn, khá rẽ tiền có thể thực hiện tại giường và làm nhiều lần. Phương tiện siêu âm được trang bị rộng rãi trong cả nước từ các bệnh viện trung ương đến các trung tâm y tế cơ sở do đó nếu sử dụng tốt vai trò của mình thì siêu âm rất có ích cho việc chẩn đoán.

Siêu âm chẩn đoán tốt cho những tổn thương tạng đặc trong ổ bụng, siêu âm có thể phát hiện dịch tự do trong ổ bụng dù một lượng không lớn ở rãnh Morrison hay túi cùng Douglas trên những bệnh nhân có võ̃ tạng rỗng nhưng độ nhạy không cao (86\%), độ đặc hiệu $(90 \%)$, giá trị tiên đoán dương (87\%) [6], [8].

Chính vì những lý trên chúng tôi tiến hành nghiên cứu này với mục tiêu khảo sát vai trò của siêu âm trong chẩn đoán chấn thương và vết thương bụng.

\section{II. ĐỐI TƯỢNG VÀ PHƯƠNG PHÁP NGHIÊN CỨU}

2.1. Đối tượng nghiên cứu: Tất cả bệnh nhân (BN) có chấn thương hoặc vết thương bụng được phẫu thuậttại khoa Ngoại Tổng quát Bệnh viện Đa khoa Sài Gòn.

2.2. Thời gian nghiên cứu: Từ $1 / 1 / 2019-$ $31 / 12 / 2020$.

2.3. Cõ̃ mẫu và chọn mẫu: Sử dụng phương pháp chọn mẫu thuận tiện.

2.4. Thiết kế nghiên cứu: nghiên cứu tiến cứu mô tảcắt ngang.

\subsection{Biến số nghiên cứu}

Các triệu chứng biểu hiện qua khám lâm sàng.

Các triệu chứng biểu hiện qua khám siêu âm: có dich, khí, số lượng, vị trí, xác định thương tổn tạng vị trí, mức độ...

Đô̂i chiếu kết quả chẩn đoán với phẫu thuật.
Đánh giá sự phù hợp của các kêt quả siêu âm: kết quả phẫu thuật là tiêu chuẩn vàng để kiểm chứng chẩn đoán trước mổ và chẩn đoán siêu âm.

2.6. Thu thập và xử lý số liệu. Số liệu được thu thập qua khai thác bệnh sử, thăm khám lâm sàng, các kết quả cận lầm sàng và hồ sơ bệnh án.

Các số liệu được mã hóa, sau đó được nhập và phân tích bằng phần mềm Stata10.0.

2.7. Vấn đề y đức. Được sự đồng thuận của người bệnh và người nhà trong việc tham gia nghiên cứu. Tất cả thông tin về vấn đề sức khỏe và thông tin cá nhân của người bệnh sẽ được bảo mật.

Nghiên cứu đã thông qua Hội đồng khoa học và đạo đức bệnh viện.

\section{KẾT QUẢ VÀ BÀN LUẬN}

Tổng cộng có 96 trường hợp chấn thương hoặc vết thương bụng được chẩn đoán và phẫu thuật tại khoa Ngoại tổng quát Bệnh Viện đa Khoa Sài Gòn từ 1/1/2019đến 31/12/2020

3.1. Đặc điểm dịch tễ học

\begin{tabular}{|c|c|c|c|}
\hline \multicolumn{2}{|c|}{ Đăc điểm } & $\mathbf{n}$ & $\%$ \\
\hline \multirow{2}{*}{ Giới tính } & Nam & 71 & 74 \\
\hline & Nũ & 25 & 26 \\
\hline \multirow{3}{*}{ Nhóm tuổi } & $16-30$ & 26 & 27,1 \\
\hline & $31-60$ & 56 & 58,3 \\
\hline & $>60$ & 14 & 14,6 \\
\hline \multirow{4}{*}{$\begin{array}{c}\text { Trình độ văn } \\
\text { hóa }\end{array}$} & Cấp 1 & 29 & 30,2 \\
\hline & Cấp 2 & 20 & 20,8 \\
\hline & Cấp 3 & 34 & 35,4 \\
\hline & Cao đằng, đại học & 13 & 13,5 \\
\hline \multirow{4}{*}{ Nghề nghiệp } & Lao động chân tay & 37 & 38,5 \\
\hline & Lao động trí óc & 27 & 28,1 \\
\hline & Học sinh, sinh viên & 14 & 14,6 \\
\hline & Khác & 18 & 18,8 \\
\hline \multirow{4}{*}{$\begin{array}{l}\text { Nguyên nhân } \\
\text { chấn thương, } \\
\text { vết thương }\end{array}$} & Tai nạn giao thông & 45 & 46,9 \\
\hline & Tai nạn lao động & 16 & 16,7 \\
\hline & Tai nạn sinh hoạt & 15 & 15,6 \\
\hline & Đã் thương & 20 & 20,8 \\
\hline \multirow{2}{*}{$\begin{array}{l}\text { Xét nghiệm } \\
\text { rượu/máu }\end{array}$} & Dương tính & 55 & 57,3 \\
\hline & Âm tính & 41 & 42,7 \\
\hline \multirow{3}{*}{$\begin{array}{l}\text { Cơ chế chấn } \\
\text { thương }\end{array}$} & Trực tiếp & 67 & 70 \\
\hline & Gián tiếp & 18 & 18,8 \\
\hline & Không rõ & 11 & 11,2 \\
\hline
\end{tabular}

Tỷ lê nam nhiều hơn nữ vì nam giới thường tham gia lao động nặng trên nhiều môi trường làm việc, người điều khiển phương tiện giao thôngvà đa số trong nhóm tuổi lao động.

Trong các nguyên nhân gây chân thương và vết thương bụng tai nạn giao thông chiếm đa số 
gần $50 \%$. Riêng nhóm bệnh nhân vết thương bụng trong nghiên cứu của chúng tôi chiếm $20 \%$ các trường hợp do đã thương là cảnh báo về tình trạng bạo lực và giải quyết mâu thuẫn trong xã hội. Kết quả này cũng tương tự các tác giả trong nước. Chúng tôi ghi nhận 55 trướng hợp (57,3\%) có xét nghiệm rượu trong máu dương tính đây cũng là nguyên nhân gây tai nạn chấn thương hay vết thương bụng kết quả này tương đồng các nghiên cứu trong nước nhưng cao hơn so với các tác giả nước ngoài.

Cơ chế chấn thương do tác nhân trực tiếp gây tăng áp lực đột ngột trong ổ bụng, bị ép giữa hai lực, thay đổi quán tính do dừng lại đột ngột trong khi sử dụng phương tiện di chuyển với tốc độ cao. Loại chấn thương này thường gây tổn thương tạng rất nặng như dập, vỡ, đứt mạch máu lớn, vỡ tạng phức tạp.

3.2. Kết quả siêu âm xác định dịch tự do
ổ bụng
\begin{tabular}{|c|c|c|c|c|}
\hline $\begin{array}{c}\text { Nghiên } \\
\text { cứu }\end{array}$ & $\begin{array}{c}\text { Tân số } \\
\text { (n) }\end{array}$ & $\begin{array}{c}\text { Độa } \\
\text { nhây } \\
\text { (\%) }\end{array}$ & $\begin{array}{c}\text { Độ đặc } \\
\text { hiệu } \\
\text { (\%) }\end{array}$ & $\begin{array}{c}\text { Giá trị } \\
\text { tiên đoán } \\
\text { âm (\%) }\end{array}$ \\
\hline Boulanger[2] & 400 & 81 & 97 & 96 \\
\hline Ingerman[4] & 97 & 75 & 96 & 92 \\
\hline Lui[6] & 55 & 92 & 95 & 84 \\
\hline $\begin{array}{c}\text { Mc } \\
\text { Kenney[7] }\end{array}$ & 996 & 88 & 99 & 98 \\
\hline $\begin{array}{c}\text { Rozycki[9] } \\
\text { Huỳnh Trung } \\
\text { Lập[5] }\end{array}$ & 470 & 79 & 96 & 95 \\
\hline Chúng tôi & 96 & 89,68 & 66,67 & 86,67 \\
\hline
\end{tabular}

Dịch ổ bụng có thể thây tại một vị trí hay nhiêu vị trí cùng lúc trên một bệnh nhân phụ thuộc vào số lượng. Dịch được phát hiện nhiều nhất ở dưới gan, kế đến là quanh lách. Ước lượng lớp dịch (bề dày rãnh Morrison) $0,5 \mathrm{~cm}$ tương đương $500 \mathrm{ml}$. Phát hiện dịch tự do trong ổ bung độ nhạy thay đổi $80-90 \%$, trong khi độ đặc hiệu $95-100 \%$ trong nghiên cứu chúng tôi độ đặc hiệu thấp hơn so với các tác giả nước ngoài.

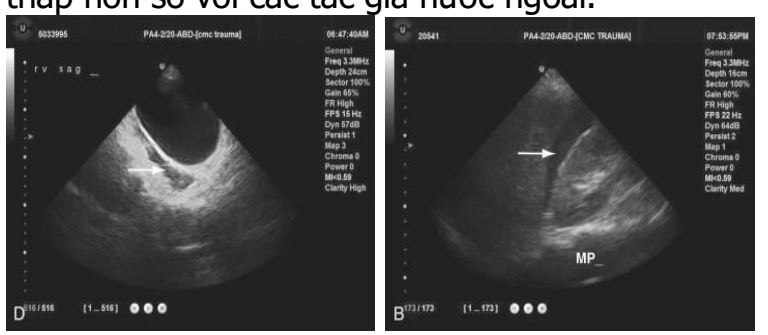

Hinh dịch ở khoang gan thận và túi cùng Douglas

3.3. Kết quả siêu âm xác định võ tạng rỗng. Siêu âm trong vỡ tạng rỗng chủ yếu là xác địSiêu âm là phương tiện hình ảnh học đầu tiên được lựa chọn cho bệnh nhân chấn thương và vết thương bụng vì thời gian tự̛c hiện nhanh, không xâm lấn, khá rẽ tiền có thể thực hiện tại giường và làm nhiều lần. Phương tiện siêu âm được trang bị rộng rãi trong cả nước từ các bệnh viện trung ương đến các trung tâm y tế cơ sở do đó nếu sử dụng tốt vai trò của mình thì siêu âm rất có ích cho việc chẩn đoán.

Siêu âm chẩn đoán tốt cho những tổn thương tạng đặc trong ổ bụng, siêu âm có thể phát hiện dịch tự do trong ổ bụng dù một lượng không lớn ở rãnh Morrison hay túi cùng Douglas trên những bệnh nhân có vỡ tạng rỗng nh khí tự do trong ổ bụng, khảo sát thương tổn thành ruột còn hạn chế. Chúng tôi ghi nhận 22 trường hợp $(22,9 \%)$ có khí tự do trong khi đó phẫu thuật xác định thêm 5 trường hợp. Siêu âm xác định võ tạng rỗng có độ nhạy $81,5 \%$, độ đặc hiệu $95,67 \%$.

Trong võ tạng rỗng mới vào trong những giờ đầu sau chấn thương siêu âm có độ chính xác không cao và phụ thuộc lượng khí trong ổ bụng. Một số trường hợp có thành bụng dày có tràn khí dưới da nên khó khảo sát. Với một số bệnh nhân nặng đa chấn thương không cho phép kéo dài thời gian làm siêu âm. Nhiêu trường hợp dạ dày ruột chướng hơi do chấn thương, liệt ruột sau sang chấn làm hạn chế khả năng phát hiện thương tổn.

3.4. Kêt quả siêu âm xác định vỡ tạng đặc

\begin{tabular}{|c|c|c|c|}
\hline Phẫu thuật & $\begin{array}{c}\text { Có vố } \\
(+)\end{array}$ & $\begin{array}{c}\text { Không } \\
\text { vớ (-) }\end{array}$ & $\begin{array}{c}\text { Tống } \\
\text { cộng }\end{array}$ \\
\hline Có vỡ (+) & 75 & 4 & 79 \\
\hline Không vỡ $(-)$ & 5 & 12 & 17 \\
\hline Tống cộng & $\mathbf{8 0}$ & $\mathbf{1 6}$ & $\mathbf{9 6}$ \\
\hline
\end{tabular}

Độ nhạy: 94,9\%; Độ đặc hiệu; 70,6\%; Độ chính xác: 90,6\%; Giá trị tiên đoán dương; 93,8\%; Giá trị tiên đoán âm: 75\%.

Theo Michihiro Sato (2004) [8] thực hiện trên 604 bệnh nhân độ nhạy của siêu âm trong phát hiện chân thương tạng đặc là 87,5\% khi được thự̛c hiện bởi chuyên gia siêu âm.

Trong chấn thương hoặc vết thương bụng chúng tôi nhận thây siêu âm có những ưu điểm: siêu âm đánh giá tập trung thương tổn (FAST) mang lại nhiêu thông tin nhanh, chính xác giúp chẩn đoán sớm từ đó đưa ra hướng xử trí và thái độ điều trị thích hợp, hiệu quả. Siêu âm còn giúp theo dõi diễn tiến chảy máu ổ bụng cấp và tiếp diễn, có ý nghĩa quan trọng trong việc quyết định phẫu thuật cấp cứu hay điều trị bảo tồn. Ngoài ra đây là phương tiện chẩn đoán hình ảnh không xâm lấn, không hại cho người bệnh, có thể thực hiện tại giường và có độ chính xác cao. Siêu âm còn giúp khảo sát dịch màng phổi, màng tim, thương tổn hệ tiết niệu, mạch máu lớn... 
Tuy niên siêu âm không phải là phương tiện chẩn đoán hình ảnh duy nhất, trong những trường hợp thương tổn phối hợp khó chẩn đoán, đôi khi phải kết hợp với các phương tiện khác như xét nghiệm huyết học, $X$ quang, CT scan, MRI, chọc dò ổ bụng, nội soi ổ bụng chẩn đoán...
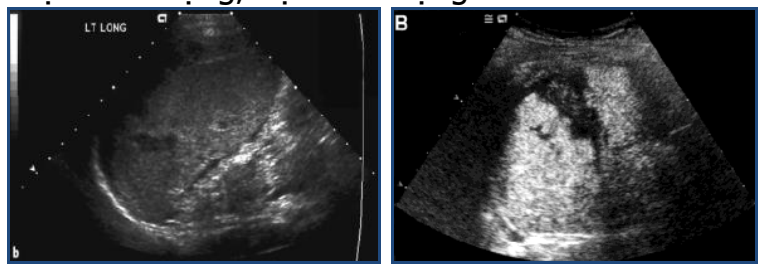

\section{Hình ảnh vỡ lách}

\section{KẾT LUÂN}

Chấn thương và vết thương bụng là cấp cứu ngoại khoa. Chẩn đoán sớm, thái độ xử lý thích hợp giúp giảm tỷ lệ tử vong.

Siêu âm đánh giá tập trung thương tổn là phương pháp chẩn đoán được lựa chơn đầu tiên giúp khảo sát thương tổn tạng trong ổ bụng.

Độ nhạy, độ chính xác của siêu âm trong chẩn đoán chấn thương và vết thương bụng khá cao.

\section{TÀI LIÊU THAM KHẢO}

1. Phạm Hòa Anh (2000), Giá trị chẩn đoán của siêu âm trong chân thương bunng kín. Luận văn Thạc sĩ y khoa. Trường Đại học Y Y dược TP.HCM.

2. Boulanger B.R (1996), Emergent abdominal sonography as creening test in a new diagnosis algorithm for blunt trauma, J Trauma Jun, 40(6): 867-74.

3. Lê Tư Hoàng (2004), Chẩn đoán và xử trí chấn thương bung kín tai Bênh viên Việt Đức 20012003, Ngoại khoa, số 5, tr 11-17.

4. Ingerman J.F. (1996), Emergency phýsicians use ultrasonography in blunt abdominal trauma. Acad Emerg Med. 3(10), p 931-937.

5. Huỳnh Trung Lập (2007), Giá trị của siêu âm trong chẩn đoán chấn thương bụng kín. Luận văn Chuyên khoa II. Trường Đai hoc Y $Y$ dước TP. HCCM.

6. Lui M. (1993), Prospective comparison of diagnosis peritoneal lavage, computed tomography scanning and ultrasonography for the diagnosis of blunt abdominal trauma. J Trauma Aug, 35(2): 267-70.

7. Mc Kenney G. (1998), Can surgeons evaluate emergency ultrasound scan for blunt abdominal trauma. J Trauma Nov, 44(4): 649-53.

8. Michihiro S. (2004), Reevaluation of ultrasonography for solid "organ injury in blunt abdominal trauma. Acad Emerg Med. 9(10), p 68-70.

\section{ĐÁNH GIÁ VI KẼ CỦA CLEARFIL AP-X COMPOSITE KHI SỬ DỤNG HAI KỸ THUẬT ĐẶT CHẤT DÁN KHÁC NHAU}

\section{TÓM TẮT}

Mục tiêu: Đánh giá khả năng làm giảm vi kẽ của hệ thổng dán Single Bond Universal Adhesive khi áp dụng kỹ thuật đặt 2 lớp keo dán chiếu đèn 1 lần và đắt 2 lớp keo dán chiếu đèn riêng từng lớp. Phương pháp nghiên cứu: Nghiên cứu thử nghiệm trong labo (in vitro) trên 30 răng cối nhỏ hàm dưới vĩnh viến của người trưởng thành, chia ngẫu nhiên thành 2 nhóm với kỹ thuât sử dung hệ thống dán Single Bond Universal Adhesive đặt 2 lớp và chiếu đèn một lần (nhóm 1), so với kỹ thuật đặt 2 lớp bond, chiếu đèn riêng cho từng lớp. Kết quả: Vi kẽ đến thành trục được quan sát thấy ở cà hai nhóm. Tuy nhiên số lượng mẫu có vi kẽ đến thành trục ở nhóm chiếu đèn tựng lớp ít hơn so với nhóm chiểu đèn 1 lần sau khi đă̆t 2 lớp chất dán (2 mẫu độ 3 ở nhóm II và 9 mẫu đổ 3 ở nhóm I). Mức độ vi kẽ ở thành nướu của phục hồi xoang II ở nhóm chiếu đèn từng lớp là ít hơn có ý nghĩa so với nhóm chiếu đèn 1 lân sau khi đặt 2 lớp

\section{*Đại học Y Dước TP HCM}

Chịu trách nhiệm chính: Nguyễn Thu Thủy

Email: ntthuy@ump.edu.vn

Ngày nhận bài: 5/3/2021

Ngày phản biện khoa học: 6/4/2021

Ngày duyệt bài: 3/5/2021

\section{Nguyễn Thu Thủy*}

chất dán $(p<0,05)$. Kết luận: Kỹ thuật đặt hai lớp chất dán và chiếu đèn cho từng lớp có thể là một biên pháp giúp khắc phục vi kẽ, một trong những thách thức lớn của phục hồi composite.

Tư khóa: Hệ thống dán Bonding, phương pháp keo dán chiếu đèn, vi kẽ.

\section{SUMMARY}

EVALUATE THE MICROLEAKAGE OF CLEARFIL AP-X COMPOSITE USING TWO DIFFERENT ADHESIVE TEACHNIQUES

Objectives: To evaluate the ability of the Single Bond Universal Adhesive system to reduce microleakage when applying 2 coats - one cure and 2 coats - two separate cures teachnique. Methods: Experimental study in the lab (in vitro) on 30 permanent lower premolars, randomly divided into 2 groups with the technique using the Single Bond Universal Adhesive system with 2 coats - one cure (group 1) and 2 coats - two separate cures (group 2). Results: Axial microleakages were observed in both groups. However, the number of samples with axial microleakages in the group of curing each layer was less than that of the one-cure group after placing 2 layers of adhesive ( 2 samples of degree 3 in group II and 9 samples of degree 3 in group I). The degree of microleakages in the gigival wall of cavities in the two- 